\title{
A Fast Independent Component Analysis Algorithm for Geochemical Anomaly Detection and Its Application to Soil Geochemistry Data Processing
}

\author{
Bin Liu, ${ }^{1,2}$ Si Guo, ${ }^{1}$ Youhua Wei, ${ }^{1,2}$ and Zedong Zhan ${ }^{1,2}$ \\ ${ }^{1}$ Geomathematics Key Laboratory of Sichuan Province, Chengdu University of Technology, Chengdu 610059, China \\ ${ }^{2}$ College of Geophysics, Chengdu University of Technology, Chengdu 610059, China \\ Correspondence should be addressed to Bin Liu; liubincim@163.com
}

Received 14 March 2014; Revised 21 June 2014; Accepted 7 July 2014; Published 24 July 2014

Academic Editor: Chongbin Zhao

Copyright (C) 2014 Bin Liu et al. This is an open access article distributed under the Creative Commons Attribution License, which permits unrestricted use, distribution, and reproduction in any medium, provided the original work is properly cited.

\begin{abstract}
A fast independent component analysis algorithm (FICAA) is introduced to process geochemical data for anomaly detection. In geochemical data processing, the geological significance of separated geochemical elements must be explicit. This requires that correlation coefficients be used to overcome the limitation of indeterminacy for the sequences of decomposed signals by the FICAA, so that the sequences of the decomposed signals can be correctly reflected. Meanwhile, the problem of indeterminacy in the scaling of the decomposed signals by the FICAA can be solved by the cumulative frequency method (CFM). To classify surface geochemical samples into true anomalies and false anomalies, assays of the 1:10 000 soil geochemical data in the area of Dachaidan in the Qinghai province of China are processed. The CFM and FICAA are used to detect the anomalies of $\mathrm{Cu}$ and $\mathrm{Au}$. The results of this research demonstrate that the FICAA can demultiplex the mixed signals and achieve results similar to actual mineralization when $85 \%$, 95\%, and $98 \%$ are chosen as three levels of anomaly delineation. However, the traditional CFM failed to produce realistic results and has no significant use for prospecting indication. It is shown that application of the FICAA to geochemical data processing is effective.
\end{abstract}

\section{Introduction}

An ore-forming system in the crust of the Earth is a highly nonlinear system, which commonly involves coupled processes between material deformation, pore-fluid flow, heat transfer, mass transport, and chemical reactions [1-9]. Because these processes can be described mathematically by a set of partial differential equations [1-3, 10-13], it is important to obtain theoretical and numerical solutions using both mathematical and computational methods in the field of applied mathematics so that the distributions of mineral resources in the upper crust of the Earth can be better predicted. For this reason, an emerging discipline known as computational geoscience $[14,15]$ has been established in recent years.

For quantitative prediction of mineral resources, geochemical data are an important information source. Researchers need the data to understand and simulate the dynamic mechanisms of ore-forming systems. Extracting prospecting information from geochemical element data is a central purpose of metallogenic prediction [16]. The geochemical element data are obtained from the field by sampling and analysis. During this process, the corresponding interferences are produced, so collecting hidden anomaly information that may reflect the spatial distribution characteristics of geochemical elements is the key to suppressing interference between geochemical elements [17-19]. Common data analysis methods are usually based on low-order statistical properties without considering the higher-order statistical characteristics of the data [20,21]. Most researchers believe that, because samples disobey the normal distribution, the existing methods cannot be directly applied to raw data analysis [22]. Moreover, due to the complexity of geological information, traditional data mining cannot reflect the spatial distribution characteristics of mineral resources because the dynamic mechanisms that control the formation of these mineral resources are completely neglected [16-22]. To better understand the geological information associated 
with geochemical data, many researchers study the spatial distribution characteristics of the elements and the physical and chemical properties of the bare geologic body [23]. As a result, several quantitative geochemical methods, such as spatial statistics, the fractal technique, discriminant analysis, and fuzzy clustering [24-28], have been developed over the past few decades. These methods are associated with the density frequency of the element and are based on the perceptions of mineralization, which may lead to false anomalies that have nothing to do with mineralization [29]. In fact, geochemical exploration data processing methods should only consider data cardinalities [30]. For example, in the independent component analysis (ICA) method, higher-order statistical features of data are taken into account [31]. The method isolates the independent source signals that are implicit in the mixed signal under "blind" conditions. In previous studies, the ICA method was mainly used for mineral predictions and is still at a fledging stage in geochemical applications [32].

Although the mathematical analysis and computational simulation methods associated with applied mathematics have been widely used to produce analytical solutions $[1-3$, 33-36] and numerical results for understanding the dynamic mechanisms and processes of ore-forming systems [4-9], this study attempts to utilize the FICAA for detecting anomalies in geochemical data. For example, Zhao and his coworkers have successfully solved a set of partial differential equations for the convective pore-fluid problems that are closely related to hydrothermal ore-forming systems $[1-3,33,34]$. They also solved a different set of partial differential equations for the chemical dissolution front instability problems that are present in many ore-forming systems within the upper crust of the Earth [37-45]. According to the FICAA and the characteristics of the geochemical data, processing raw geochemical data with the FICAA can solve the sequence indeterminacy problem of separated results caused by the FICAA by calculating the correlation coefficient matrix of raw data and separating the independent components. In addition, the cumulative frequency method is used to solve the indeterminacy problem in scaling by direct comparison to the resultant anomalies. When a late prospecting trench validation is conducted, the data (after FICAA processing) can be used to better reflect the spatial distribution characteristics of the elements. This can provide useful geological information for understanding and simulating the dynamic mechanisms of ore-forming systems [14, 15].

This paper is organized as follows. The principles of the FICAA and the correlation coefficient algorithm are introduced in Section 2. A brief introduction of the geological background of the area around Dachaidan in the Qinghai province of China is given in Section 3. The FICAA is applied to the 1:10000 soil geochemical data of this area in Section 4 . The results are discussed and conclusions are stated in Sections 5 and 6 , respectively.

\section{Algorithm Principle}

2.1. The Problem Description of Independent Component Anal$y$ sis. Independent component analysis (ICA) is a data mining

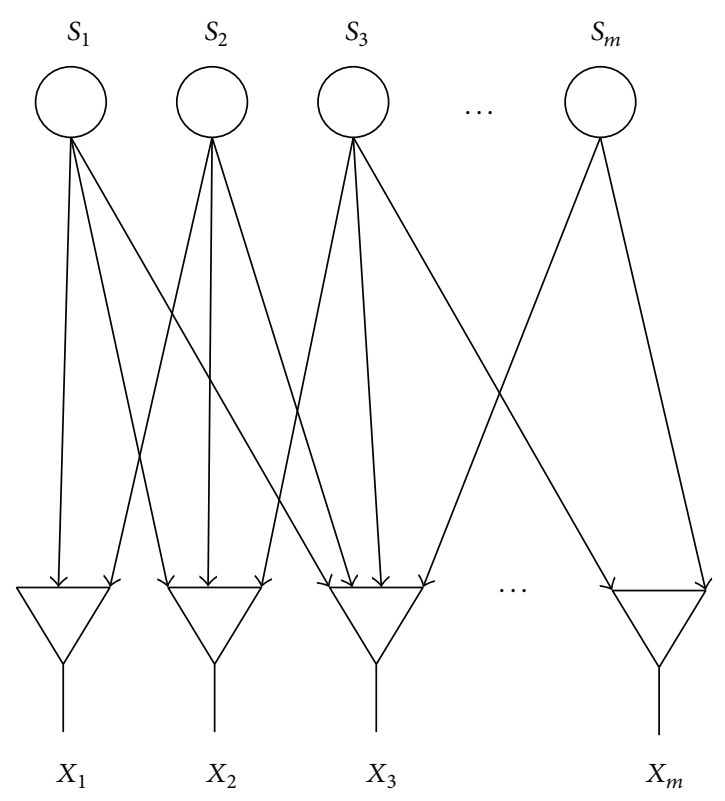

FIGURE 1: Signal mixing process.

technique that, based on the hypothesis of statistical independence, analyzes data from a perspective of higher-order statistical correlation [46]. A set of random initial vectors approximates the independent signal source implicated in the mixed signal by "decomposing" the mixed signal. Each mixed signal is a linear combination of original signals (Figure 1). The basic mathematical model of the ICA is as follows:

$$
x=A s,
$$

where $x$ denotes some observed mixed signals, matrix $A$ represents the mixing matrix of the system, and vector $s$ represents unknown source signals that are assumed to be statistically independent.

When the source signals $s$ and the mixed matrix $A$ are both unknown, only $x$ can be obtained. The ICA algorithm is designed to determine a matrix $W$ such that

$$
y=W x
$$

where $y$ is an optimal estimate of the source signals $s$. The linear solution of the ICA model can be obtained with (1) and (2). Consider

$$
y=W A s=G s
$$

where $G=W A$ is an $n \times n$ identity matrix.

In the late 1980s, Jutten and Herault proposed the concept of the ICA [47]. In 1994, Comon extended the principal component analysis, based on data processing and compression, as an independent component analysis algorithm and proposed independent component analysis based on the minimum of mutual information [48]. In 2001, Hyvärinen et al. proposed an algorithm for extracting the fixed-point from a blind signal, also called the fast ICA (FICA). In 2012, Yu et al. applied the FICA to mineral prediction [32]. However, both 
the dynamic mechanisms and the processes of ore-forming systems were completely neglected in their studies [32, 47, 48]. This is the main shortcoming of the existing method used to treat geochemical data with statistical mathematics rather than simulating the dynamic mechanisms and the processes of ore-forming systems using applied mathematics $[49,50]$.

2.2. The Data Requirements of the ICA Algorithm. First, the ICA requires that each source signal be a random signal with a zero mean value, which is statistically independent at any moment, although geochemical data are usually spatially correlated. Thus, we should obtain various results due to the spatial correlation when the ICA is used. Second, it requires an equal number of source signals and mixed signals (namely, it requires that the relationship among geochemical elements is a linear combination). Third, it requires that, at most, one source signal obey the Gaussian distribution. In practice, the influence of the "noise" is usually not considered.

2.3. The FICAA. The rationale of the FICAA is to determine a target function by maximizing negentropy and to obtain the optimal value of the target function by using Newton's iterative method.

Negentropy can be used to measure the non-Gaussianity. The negentropy of a random variable $y$ is given by

$$
J(y)=H\left(y_{\text {gauss }}\right)-H(y),
$$

where $H(\cdot)$ is the entropy function and $y_{\text {gauss }}$ and $y$ are the Gaussian variable and the random variable, respectively, with the same mean and normalized variance. If negentropy is zero, then $y$ obeys the Gaussian distribution. If $y$ is a non-Gaussian distribution, negentropy must exceed zero. A non-Gaussian measurement reaches its maximum when negentropy is maximized. Meanwhile, the optimal estimation of source signals is accomplished. The approximate formula of negentropy can be written as follows:

$$
J(y) \propto\left[E\{G(y)\}-E\left\{G\left(y_{\text {gauss }}\right)\right\}\right]^{2},
$$

where $G(\cdot)$ is an arbitrary non-quadratic function. After iterative trials, it was discovered that the rate of convergence is faster and the convergence effect is better when $G(y)=y^{4} / 4$.

To maximize negentropy, the optimal $E\left\{G\left(w^{T} x\right)\right\}$ must be achieved. According to the Kuhn-Tucker conditions, under the constraint $E\left\{G\left(w^{T} x\right)^{2}\right\}=\|w\|^{2}=1$, the optima are obtained at points where the gradient of the Lagrangian is zero:

$$
E\left\{x g\left(w^{T} x\right)\right\}-\beta x=0,
$$

where $\beta$ is a constant that can be easily evaluated as $\beta=$ $E\left\{w_{0}^{T} x g\left(w_{0}^{T} x\right)\right\}, w_{0}$ is the value of $w$ at an optimum, and $g(\cdot)$ is the first order derivative function of $G(\cdot)$. Assuming the data are bounded, $E\left\{x^{T} x\right\}=I$, the left part of (6), can be written as $F$ and we can obtain the Jacobian matrix $J F(w)$ as

$$
J F(w)=E\left\{x x^{T} g^{\prime}\left(w^{T} x\right)\right\}-\beta I .
$$

To simplify the matrix inversion, we can reasonably approximate the first item of (7) as

$$
\begin{aligned}
E\left\{x x^{T} g^{\prime}\left(w^{T} x\right)\right\} & \approx E\left\{x x^{T}\right\} E\left\{g^{\prime}\left(w^{T} x\right)\right\} \\
& =E\left\{g^{\prime}\left(w^{T} x\right)\right\} I .
\end{aligned}
$$

If $w_{0}$ is approximated as $w$ in $\beta$, then $J F(w)$ is transformed into a diagonal matrix. Thus, we can obtain the approximate Newton iterative formula as

$$
\begin{gathered}
w^{*}=w-\frac{\left[E\left\{x g\left(w^{T} x\right)\right\}-\beta w\right]}{\left[E\left\{g^{\prime}\left(w^{T} x\right)\right\}-\beta\right]}, \\
w=\frac{w^{*}}{\left\|w^{*}\right\|},
\end{gathered}
$$

where $w^{*}$ is the new value of $w$ and $\beta=E\left\{w^{T} x g\left(w^{T} x\right)\right\}$. After simplification, we can derive the iterative formula of the FICAA:

$$
\begin{gathered}
w^{*}=E\left\{x g\left(w^{T} x\right)\right\}-E\left\{g^{\prime}\left(w^{T} x\right)\right\} w, \\
w=\frac{w^{*}}{\left\|w^{*}\right\|} .
\end{gathered}
$$

2.4. The Correlation Coefficient Matrix. The FICAA is limited in the fact that separated signal sequences do not correspond one-to-one with the order of the source signals. In the absence of any other prior knowledge, this problem cannot be solved. In this paper, we use the correlation coefficient matrix to solve it.

Let $\left(X_{1}, X_{2}, X_{3}, \ldots, X_{n}\right)$ be one-dimensional random variables. If arbitrary $X_{i}$ and $X_{j}$ have the correlation coefficient $\rho_{i j}(i, j=1,2, \ldots, n)$, then an $n \times n$ matrix with elements $\rho_{i j}$ is the correlation coefficient matrix $(R)$ of $\left(X_{1}, X_{2}, X_{3}, \ldots, X_{n}\right)[51-53]$. Consider

$$
R=\left[\begin{array}{cccc}
\rho_{11} & \rho_{12} & \cdots & \rho_{1 n} \\
\rho_{21} & \rho_{22} & \cdots & \rho_{2 n} \\
\vdots & \vdots & \vdots & \vdots \\
\rho_{n 1} & \rho_{n 2} & \cdots & \rho_{n n}
\end{array}\right]
$$

where $\rho_{i j}=\operatorname{cov}\left(X_{i}, X_{j}\right) / \sqrt{D X_{i}} \sqrt{D X_{j}}, \operatorname{cov}\left(X_{i}, X_{j}\right)=E\left\{\left[X_{i}-\right.\right.$ $\left.\left.E\left\{X_{i}\right\}\right] \times\left[X_{j}-E\left\{X_{j}\right\}\right]\right\}$.

To restore the source signals of independent components, mixed signals and separated independent components are taken as new observed data to calculate the correlation coefficient matrix. The two variables of maximum absolute values with the same correlation coefficient are deemed to have a corresponding relation to each other.

\section{Geology of the Research Area}

The research area is situated in the Qinghai province of China, $700 \mathrm{~km}$ east of Xining and $35 \mathrm{~km}$ west of Dachaidan. The 1:10000 geographical coordinates cover the eastern longitude range from $95^{\circ} 47^{\prime} 51^{\prime \prime}$ to $95^{\circ} 58^{\prime} 18^{\prime \prime}$ and the northern latitude range from $37^{\circ} 42^{\prime} 44^{\prime \prime}$ to $37^{\circ} 45^{\prime} 14^{\prime \prime}$. The study area is approximately $6 \mathrm{~km}^{2}$. The strata known in the area 
TABLE 1: Parameters of soil geochemical elements in the given area of Qinghai.

\begin{tabular}{lccccccc}
\hline Element & Sample number & Min & Max & Mean & StDev & Skew & Kurtosis \\
\hline $\mathrm{Au}$ & 3307 & 0.2 & 410.0 & 7.508 & 18.6540 & 9.530 & 130.097 \\
$\mathrm{~Pb}$ & 3307 & 2.3 & 1331.0 & 17.398 & 33.5077 & 24.929 \\
$\mathrm{Zn}$ & 3307 & 20.0 & 184 & 66.86 & 18.615 & 1.137 & 213.833 \\
$\mathrm{Cu}$ & 3307 & 4.3 & 89.6 & 24.959 & 9.8264 & 1.481 & 4.340 \\
$\mathrm{As}$ & 3307 & 2.0 & 1623.0 & 40.898 & 65.6605 & 8.318 \\
$\mathrm{Sb}$ & 3307 & 0.2 & 134.00 & 2.0290 & 3.26852 & 22.701 & 826.105 \\
\hline
\end{tabular}

TABLE 2: Results of the Kolmogorov-Smirnov test on the variables.

\begin{tabular}{lccr}
\hline Element & Kolmogorov-Smirnov $Z$ & Asymp. Sig. (2-tailed) & Distribution \\
\hline $\mathrm{Pb}$ & 20.782 & $<0.01$ & Nonnormal \\
$\mathrm{Au}$ & 20.251 & $<0.01$ & Nonnormal \\
$\mathrm{Cu}$ & 6.078 & $<0.01$ & Nonnormal \\
$\mathrm{Zn}$ & 5.923 & $<0.01$ & Nonnormal \\
$\mathrm{As}$ & 16.895 & $<0.01$ & Nonnormal \\
$\mathrm{Sb}$ & 17.893 & $<0.01$ & Nonnormal \\
\hline
\end{tabular}

are the Silurian (S), Permian (P), and Quaternary $\left(\mathrm{Q}_{4}\right)$. Rock types are conglomerate, altered conglomerate, sandstone, quartz schist, altered quartz schist, arkose quartzite, lithic sandstone, slate, and phyllite. The mineralizations are silicification, ferritization, pyritization, malachitization, and chalcopyritization. The study area mainly consists of an Au mineralization belt and a $\mathrm{Cu}$ mineralization belt. The Au belt is mainly distributed in the Permian stratus and the $\mathrm{Cu}$ belt is primarily found in the Silurian stratus (Figure 2). The major minerals in this area are galena, malachite, and azurite.

\section{Application}

The project involved setting up 34 soil geochemical profile lines and completing $6 \mathrm{~km}^{2}$ of soil geochemical surveys. The sampling network is $100 \mathrm{~m} \times 20 \mathrm{~m}$. Soil geochemical samples included 3307 samples that were analyzed for six elements: $\mathrm{Au}, \mathrm{Cu}, \mathrm{Pb}, \mathrm{As}, \mathrm{Sb}$, and $\mathrm{Zn}$. In this study area, ten prospecting trenches were dug and 200 samples were collected and notched. Based on descriptive statistics analysis of soil geochemical data, characteristics indexes were determined and are shown in Table 1 ( $\mathrm{Au}$ is reported in $\mathrm{ppb}$ and the remaining metals are reported in ppm).

The existing geochemical data processing methods frequently rely on the assumption that geochemical data obey a normal distribution. However, the spatial distribution of geochemical element content is very complex, so existing methods have limitations. Because the FICAA requires that only the contents of one element obey the normal distribution, the first analysis of this framework examines the probability plots reported in Figure 3. The purpose is to verify whether the raw data obey a normal distribution. Figure 3 shows that $\mathrm{Au}, \mathrm{Pb}, \mathrm{As}$, and $\mathrm{Sb}$ obviously disobey the normal distribution. Meanwhile, $\mathrm{Cu}$ and $\mathrm{Zn}$ approximately obey a normal distribution.

Graphical tools can support hypothesis tests for normality. The results of the tests for $\mathrm{Cu}$ and $\mathrm{Zn}$ are controversial, as
TABLE 3: Correlation coefficient results.

\begin{tabular}{lcccccc}
\hline Variable & $\mathrm{Au}$ & $\mathrm{Cu}$ & $\mathrm{Pb}$ & $\mathrm{Zn}$ & $\mathrm{As}$ & $\mathrm{Sb}$ \\
\hline$y 1$ & -0.213 & -0.124 & -0.982 & 0.019 & -0.067 & 0.002 \\
$y 2$ & 0.001 & -0.018 & -0.006 & -0.021 & 0.009 & -0.985 \\
$y 3$ & 0.040 & 0.086 & 0.020 & 0.135 & 0.949 & 0.081 \\
$y 4$ & -0.967 & 0.050 & 0.099 & 0.046 & -0.169 & -0.092 \\
$y 5$ & 0.047 & -0.546 & -0.092 & 0.097 & 0.031 & -0.082 \\
$y 6$ & 0.128 & -0.822 & -0.130 & -0.985 & 0.256 & -0.087 \\
\hline
\end{tabular}

expected (Figure 3). Furthermore, the Kolmogorov-Smirnov (K-S) normal distribution test is conducted on the soil sample data. Table 2 shows that the normality hypothesis cannot be accepted $(P<0.05)$ because the contents of the six elements disobey the normal distribution. Thus, these data meet the basic requirement of the FICAA.

Based on the FICAA and the statistical independence of the raw geochemical data, we consider the six element content values as the mixed signals (the raw data). The oscillogram of the raw data is shown in Figure 4 and the oscillogram of the source signals after separation by the FICAA is shown in Figure 5. Because the FICAA is a copy or estimation of the source signals, the sequences and scaling of the source signals have changed. The changes are displayed in the oscillogram of the separated results. We introduce the correlation coefficient to solve this problem.

As clearly demonstrated in Figure 5, the waveforms of the six elements after separation correspond to the waveforms of the raw data. Treating the survey data and independent components as new observation variables, we calculate the correlation coefficient between them. The correlation coefficient results in Table 3 show that the maximum absolute values of each column are $0.967,0.546,0.982,0.985,0.949$, and 0.985 , respectively. Thus, it can be concluded that $y 1, y 2$, $y 3, y 4, y 5$, and $y 6$ correspond to $\mathrm{Pb}, \mathrm{Sb}, \mathrm{As}, \mathrm{Au}, \mathrm{Cu}$, and $\mathrm{Zn}$. 

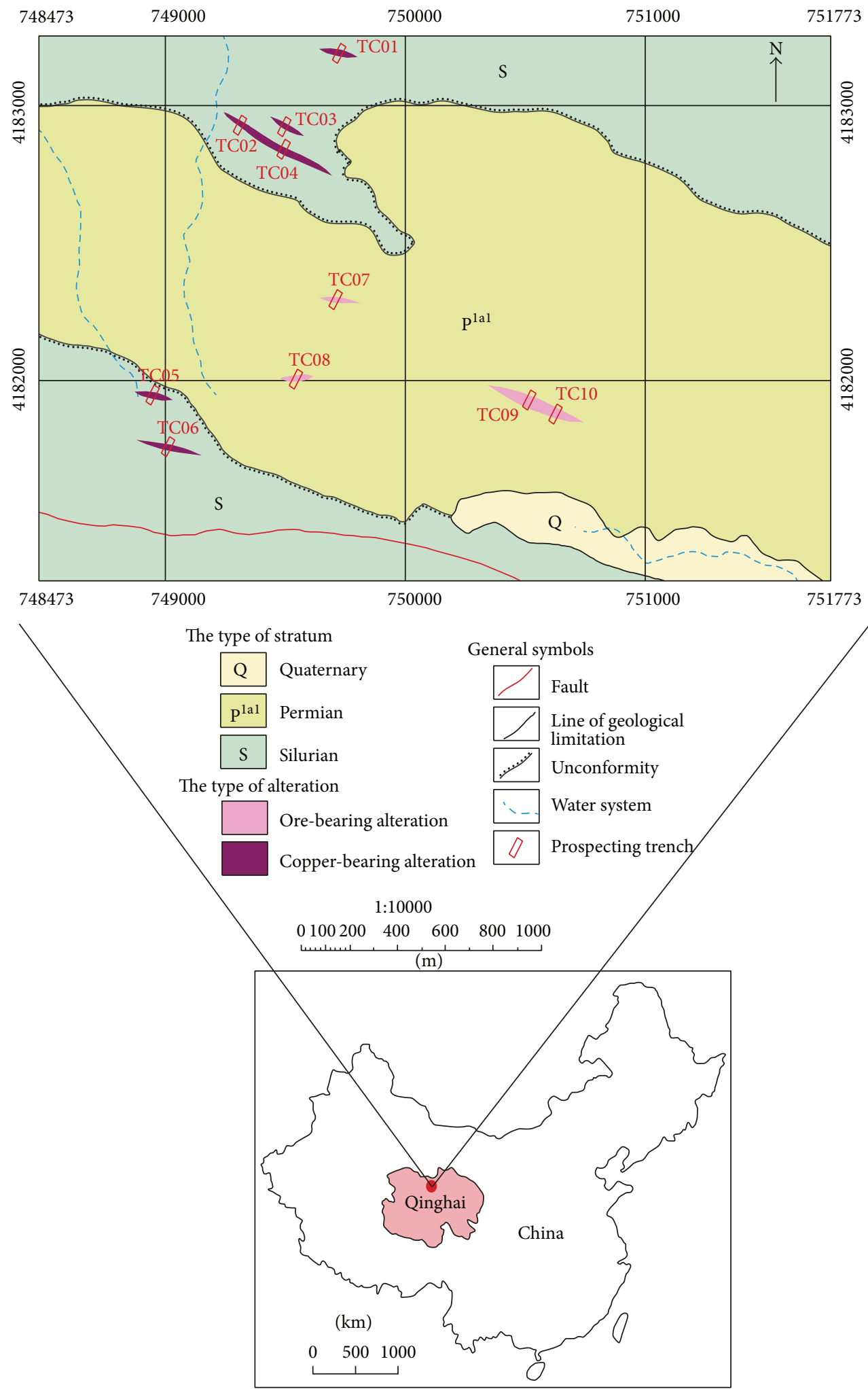

- Study area

FIGURE 2: Simplified geological map and location map of the study area with alterations. 

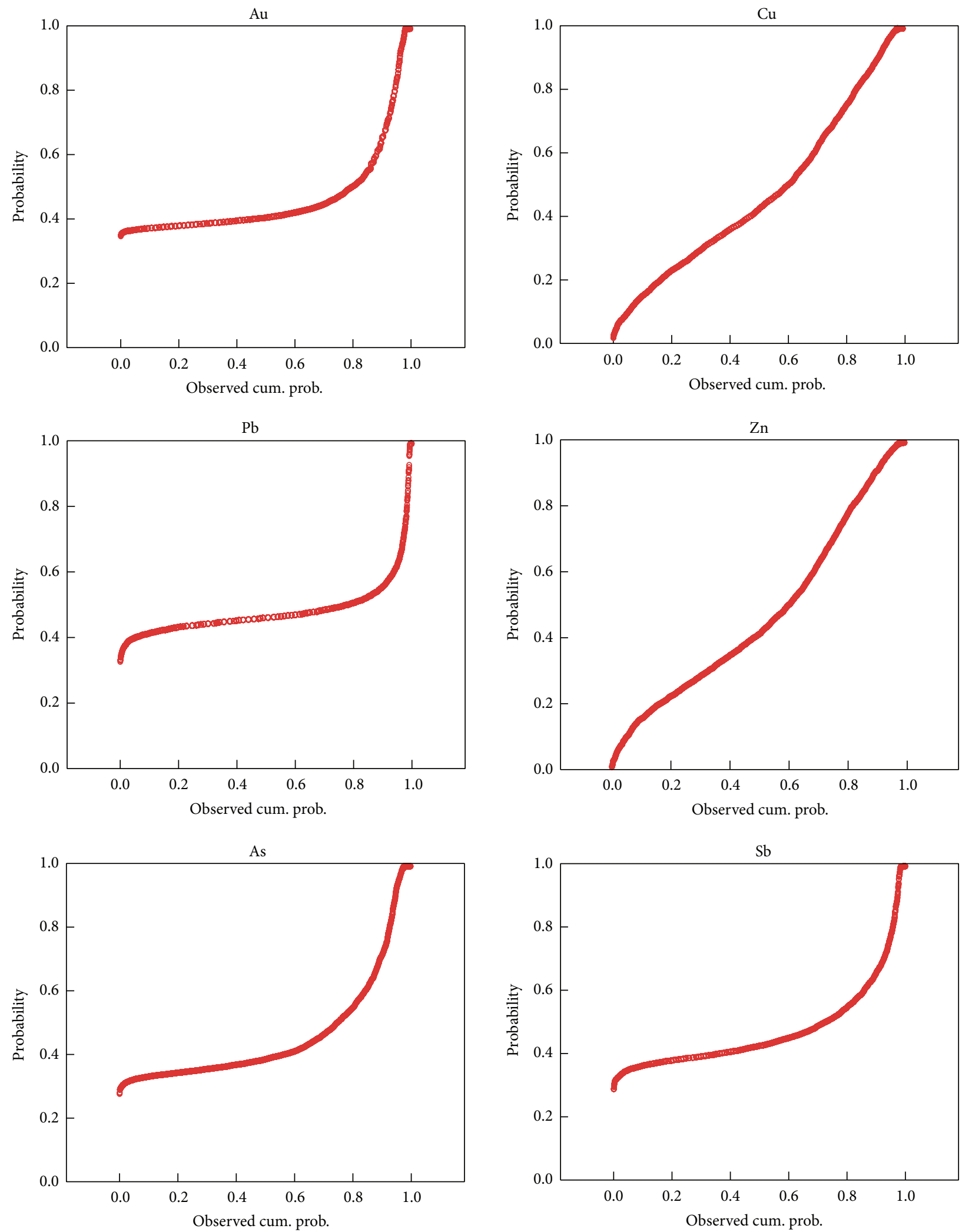

FIgURE 3: Normal probability plots of $\mathrm{Au}, \mathrm{Cu}, \mathrm{Pb}, \mathrm{Zn}, \mathrm{As}$, and $\mathrm{Sb}$. 

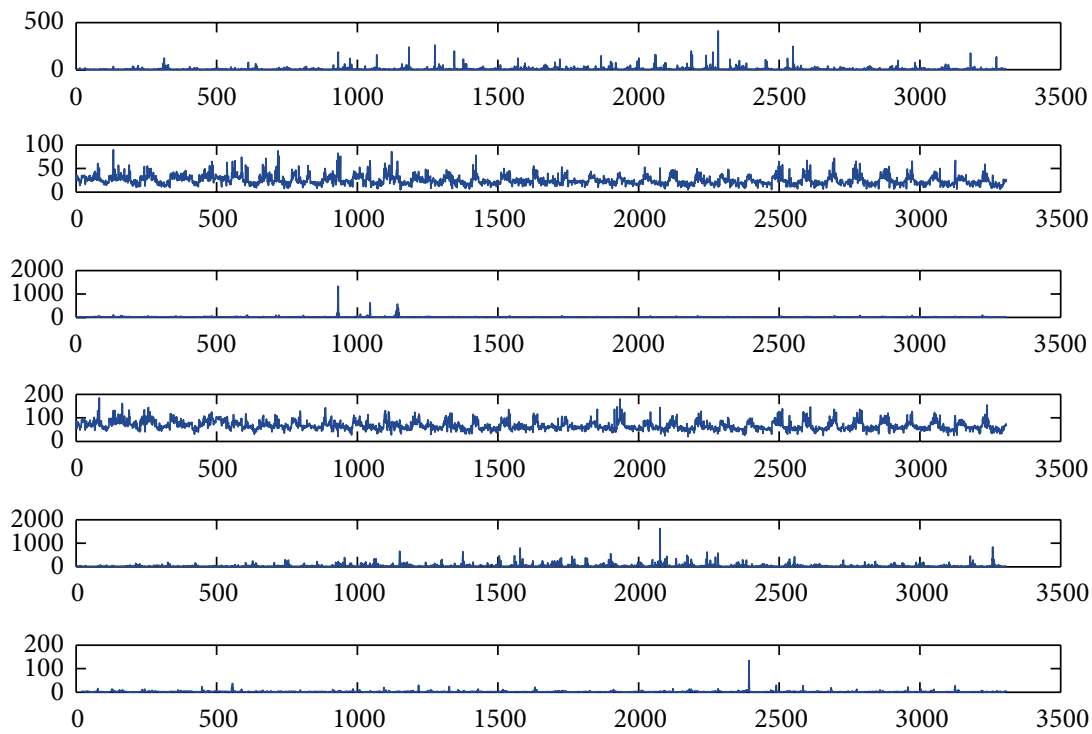

Figure 4: Oscillogram of the raw data.
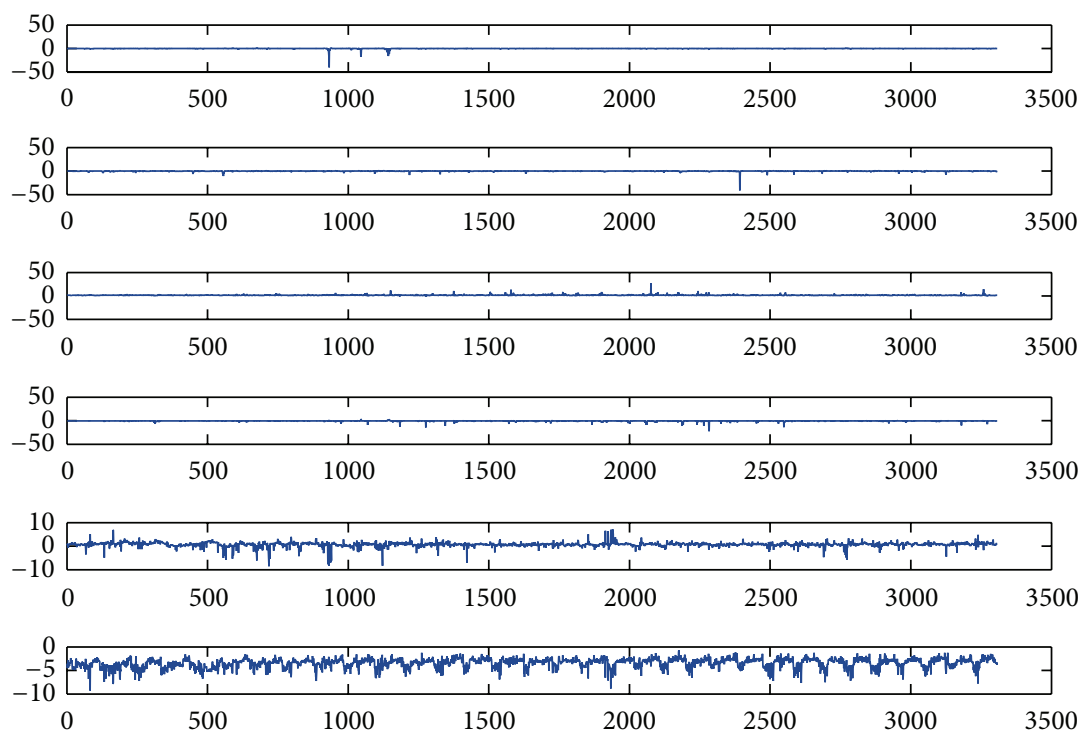

FIGURE 5: Oscillogram of the data separated by the FICAA.

FICAA processing is only a copy or estimation of the raw data and only reflects the general trend of the data. The cumulative frequency method is employed to determine the distribution characteristics of the elements and to solve the problem of sequence indeterminacy. Selecting $85 \%, 95 \%$, and $98 \%$ as the intrazone, mesozone, and external zone of the anomaly, the isograms of the raw data and separated data are depicted using the cumulative frequency method. Their three-level cumulative frequencies are given in Table 4. Because this study mainly analyzes the metallogenic elements $\mathrm{Au}$ and $\mathrm{Cu}$, Figures 6 through 9 show the $\mathrm{Au}$ and $\mathrm{Cu}$ isograms of the raw data and data separated by the FICAA, respectively.

\section{Discussion}

The anomaly analysis of $\mathrm{Au}$ and $\mathrm{Cu}$ and the prospecting trench work are carried out based on the anomaly isograms. The anomaly isograms show that $\mathrm{Au}$ is mainly distributed in the Permian while $\mathrm{Cu}$ mostly spreads over the Silurian. There are obvious differences between the isograms of $\mathrm{Au}$ and $\mathrm{Cu}$ that are delineated by the raw data and the FICAA processed data. Test and analysis results are shown in Table 5. In trench TC04, the element content of Au is 0.1, where the raw data of $\mathrm{Au}$ has an obvious anomaly, but the FICAA processed data does not. The FICAA processed result is consistent with the 


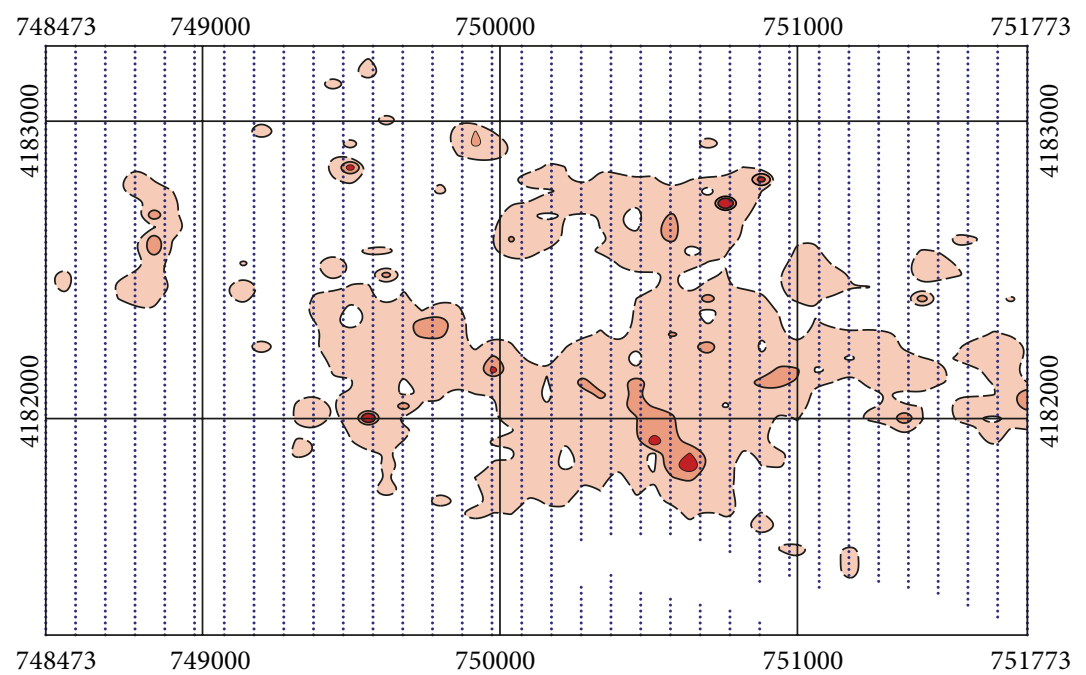

- Soil sample

$\mathrm{Au}$

$\square 10$

$\square 25$

52

FIGURE 6: The isogram of Au.

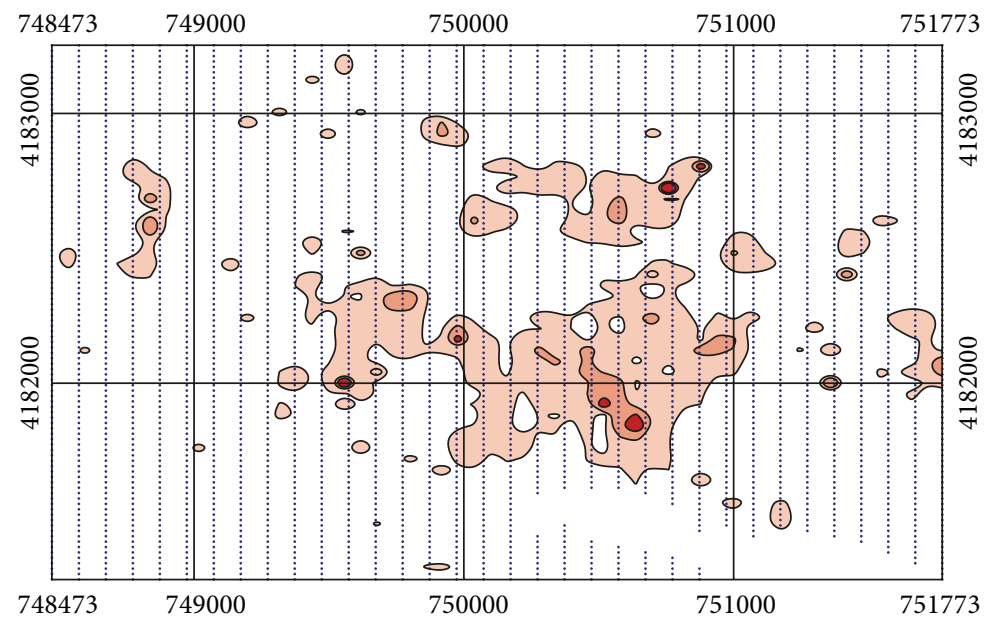

- Soil sample

$\mathrm{Au}$

$\square 0.87$

$\square 1.57$

2.88

FIGURE 7: The isogram of Au after processing by the FICAA.

TABLE 4: Zoning sequences delineated by the cumulative frequency.

\begin{tabular}{lcccccccccccc}
\hline Zoning & $\mathrm{Au}$ & $\mathrm{Cu}$ & $\mathrm{Pb}$ & $\mathrm{Zn}$ & $\mathrm{As}$ & $\mathrm{Sb}$ & $y 1$ & $y 2$ & $y 3$ & $y 4$ & $y 5$ & $y 6$ \\
\hline Exozone & 9.8 & 34 & 19.5 & 85.4 & 59.2 & 2.75 & 0.2379 & 0.4269 & 1.6729 & 0.8691 & -0.151 & 4.4311 \\
Mesozone & 25.1 & 42.9 & 27.9 & 102 & 135 & 4.49 & 0.4289 & 0.889 & 2.6092 & 1.5673 & 0.6145 & 5.2717 \\
Intrazone & 52 & 50.9 & 41.5 & 115 & 227 & 7.98 & 0.871 & 1.935 & 4.0833 & 2.883 & 1.7436 & 5.9494 \\
\hline
\end{tabular}




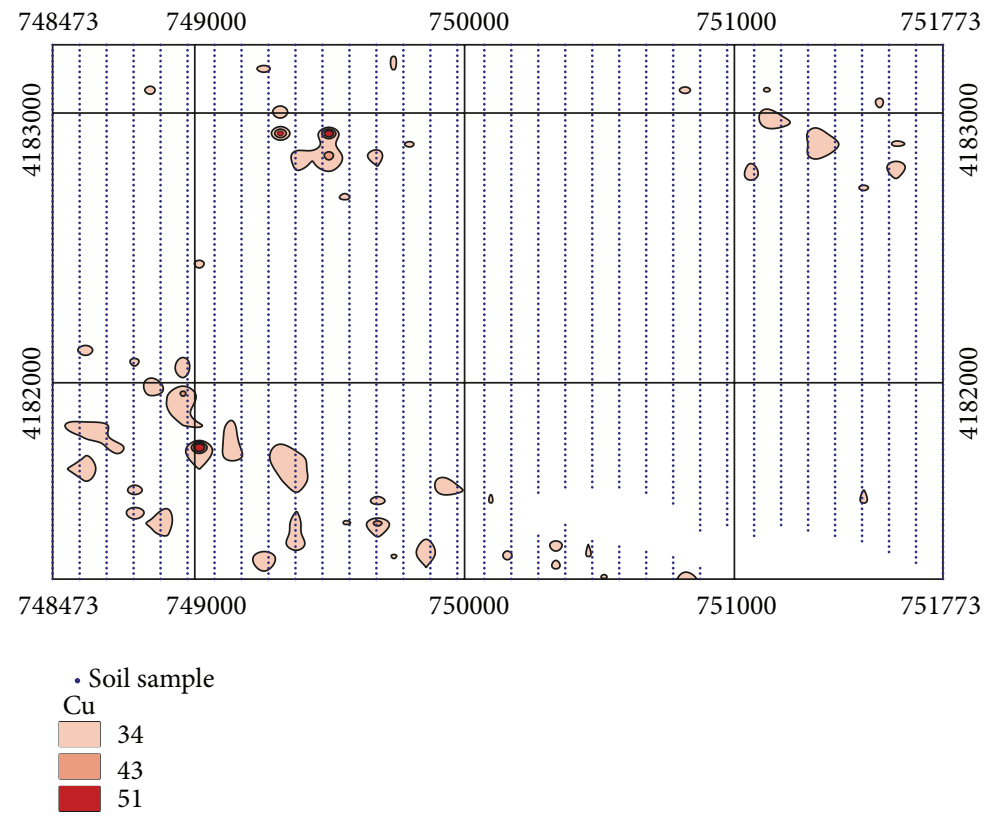

Figure 8: The isogram of $\mathrm{Cu}$.

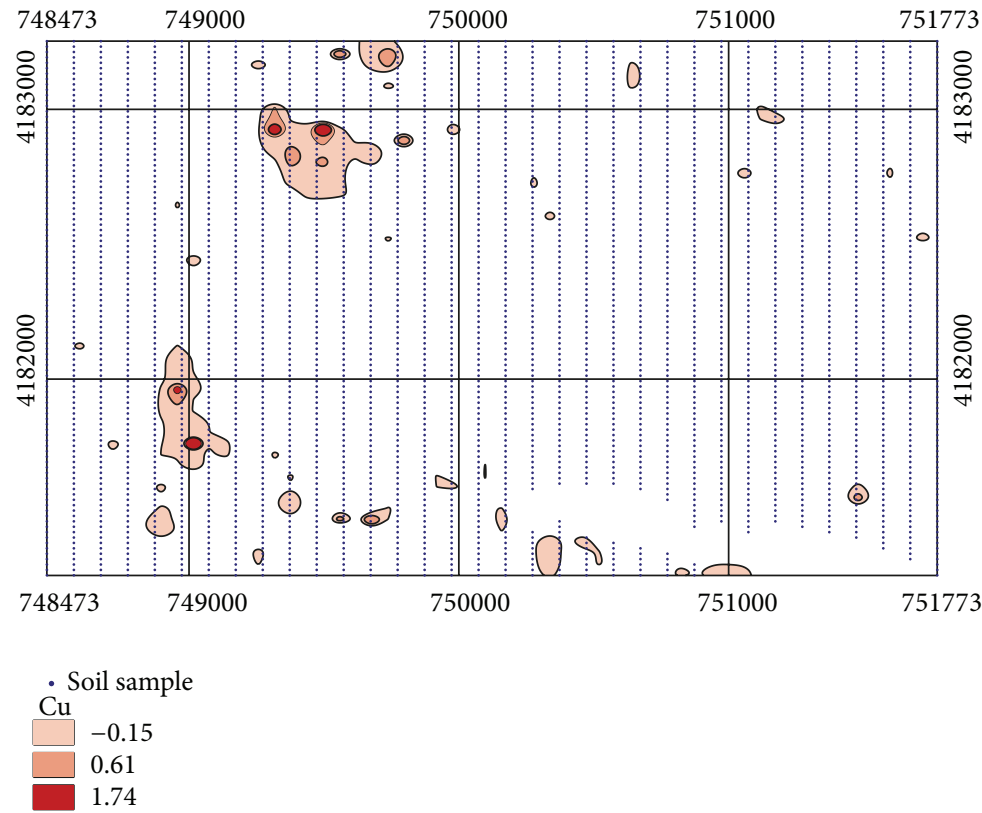

FIgURE 9: The isogram of $\mathrm{Cu}$ after processing by the FICAA.

actual situation. In trenches TC01 and TC05, the element contents of $\mathrm{Cu}$ are 0.15 and 1.99. The raw data show normal distributions, while the FICAA processed data reveal apparent anomalies that match the true conditions. Meanwhile, other trenches reasonably show the distribution abnormalities of $\mathrm{Au}$ and $\mathrm{Cu}$. Thus, employing the FICAA to process the geochemical data can better reflect the spatial distribution characteristics of elements. This is because when the existing statistical data processing method is used, we must assume that the data obey the normal distribution or lognormal distribution. However, the actual geochemical data may not satisfy this assumption. Therefore, these existing methods have limitations. The FICAA can preprocess the geochemical data under unknown circumstances. This can eliminate the mutual interference between elements so that the data may provide a clearer direction for geochemical data processing.

The analysis results show that the anomaly isograms processed by the FICAA are more in line with the actual element distributions. Although we solve the problem of scaling indeterminacy, the anomalies still cannot be displayed directly by the processed data. Moreover, the FICAA should be verified in other geological areas. 
TABLE 5: The analysis results of chemical groove samples.

\begin{tabular}{lcc}
\hline Serial number of trench & Au $(\max )$ & $\mathrm{Cu}(\max )$ \\
\hline TC01 & $<0.10$ & 0.15 \\
TC02 & $<0.10$ & 1.05 \\
TC03 & $<0.10$ & 0.19 \\
TC04 & $<0.10$ & 2.14 \\
TC05 & $<0.10$ & 1.99 \\
TC06 & $<0.10$ & 0.5 \\
TC07 & 0.37 & $<0.01$ \\
TC08 & 0.45 & $<0.01$ \\
TC09 & 1.69 & $<0.01$ \\
TC10 & 1.61 & $<0.01$ \\
\hline
\end{tabular}

More importantly, the existing geochemical data processing methods with the statistical mathematics characteristic (such as the FICAA used in this study) cannot be used to simulate the dynamic mechanisms and processes of oreforming systems, so they are invalid for predicting concealed ore deposits within the upper crust of the Earth. To solve this problem, applied mathematics methods have been used to establish an emerging discipline, known as computational geoscience, during most of the past two decades. As a result, computational simulation methods have become important tools not only for simulating the dynamic mechanisms and processes of ore-forming systems but also for predicting the potential locations of ore deposits within the upper crust of the Earth $[14,15,49]$.

\section{Conclusions}

This study identifies soil geochemistry anomaly areas based on the presence or absence of mineralization in trench samples. Use of the correlation coefficient and the cumulative frequency can solve indeterminacy problems in both sequences and scaling. Comparing FICAA processed raw data to the results of the CFM beforehand can better reflect the distribution characteristics of the geochemical elements. Because geological backgrounds are different when the study areas are different, the geochemical exploration method should be applied on the basis of the actual situation.

The existing geochemical data processing methods with the statistical mathematics characteristic (such as the FICAA used in this study) cannot be used to simulate the dynamic mechanisms and processes of ore-forming systems; therefore, they are invalid for predicting concealed ore deposits within the upper crust of the Earth. Because computational geoscience methods with the applied mathematics characteristic can effectively simulate the dynamic mechanisms and processes of ore-forming systems, they should be used in future research to predict potential locations of ore deposits within the upper crust of the Earth.

\section{Conflict of Interests}

The authors declare that there is no conflict of interests regarding the publication of this paper.

\section{Acknowledgment}

This research is supported by the National Natural Science Foundation of China (Grant no. 41272363).

\section{References}

[1] C. Zhao, H. B. Mühlhaus, and B. E. Hobbs, "Finite element analysis of steady-state natural convection problems in fluidsaturated porous media heated from below," International Journal for Numerical and Analytical Methods in Geomechanics, vol. 21, no. 12, pp. 863-881, 1997.

[2] C. Zhao, B. E. Hobbs, and H. B. Mühlhaus, "Finite element modelling of temperature gradient driven rock alteration and mineralization in porous rock masses," Computer Methods in Applied Mechanics and Engineering, vol. 165, no. 1-4, pp. 175187, 1998.

[3] C. Zhao, B. E. Hobbs, and H. B. Mühlhaus, "Theoretical and numerical analyses of convective instability in porous media with upward throughflow," International Journal for Numerical and Analytical Methods in Geomechanics, vol. 23, no. 7, pp. 629646, 1999.

[4] B. E. Hobbs, Y. Zhang, A. Ord, and C. Zhao, "Application of coupled deformation, fluid flow, thermal and chemical modelling to predictive mineral exploration," Journal of Geochemical Exploration, vol. 69-70, pp. 505-509, 2000.

[5] A. Ord, B. E. Hobbs, Y. Zhang et al., "Geodynamic modelling of the Century deposit, Mt Isa Province, Queensland," Australian Journal of Earth Sciences, vol. 49, no. 6, pp. 1011-1039, 2002.

[6] P. Sorjonen-Ward, Y. Zhang, and C. Zhao, "Numerical modelling of orogenic processes and gold mineralisation in the southeastern part of the Yilgarn Craton, Western Australia," Australian Journal of Earth Sciences, vol. 49, no. 6, pp. 935-964, 2002.

[7] P. A. Gow, P. Upton, C. Zhao, and K. C. Hill, “Copper-gold mineralisation in New Guinea: numerical modelling of collision, fluid flow and intrusion-related hydrothermal systems," Australian Journal of Earth Sciences, vol. 49, no. 4, pp. 753-771, 2002.

[8] P. M. Schaubs and C. Zhao, "Numerical models of gold-deposit formation in the Bendigo-Ballarat Zone, Victoria," Australian Journal of Earth Sciences, vol. 49, no. 6, pp. 1077-1096, 2002.

[9] Y. Zhang, B. E. Hobbs, A. Ord et al., "The influence of faulting on host-rock permeability, fluid flow and ore genesis of gold deposits: a theoretical 2D numerical model," Journal of Geochemical Exploration, vol. 78-79, pp. 279-284, 2003.

[10] C. Zhao, B. E. Hobbs, A. Ord, S. Peng, H. B. Mühlhaus, and L. Liu, "Theoretical investigation of convective instability in inclined and fluid-saturated three-dimensional fault zones," Tectonophysics, vol. 387, no. 1-4, pp. 47-64, 2004.

[11] C. Zhao, B. E. Hobbs, A. Ord, P. Hornby, S. Peng, and L. Liu, "Mineral precipitation associated with vertical fault zones: the interaction of solute advection, diffusion and chemical kinetics," Geofluids, vol. 7, no. 1, pp. 3-18, 2007.

[12] C. Zhao, B. E. Hobbs, and A. Ord, Convective and Advective Heat Transfer in Geological Systems, Springer, Berlin, Germany, 2008.

[13] C. Zhao, Dynamic and Transient Infinite Elements: Theory and Geophysical, Geotechnical and Geoenvironmental Applications, Advances in Geophysical and Environmental Mechanics and Mathematics, Springer, Berlin, Germany, 2009.

[14] C. Zhao, B. E. Hobbs, and A. Ord, "Investigating dynamic mechanisms of geological phenomena using methodology of 
computational geosciences: an example of equal-distant mineralization in a fault," Science in China D: Earth Sciences, vol. 51, no. 7, pp. 947-954, 2008.

[15] C. Zhao, B. E. Hobbs, and A. Ord, Fundamentals of Computational Geoscience: Numerical Methods and Algorithms, Springer, Berlin, Germany, 2009.

[16] S. C. Wang, Theory and Methods of Mineral Resources Prediction Based on Synthetic Information, Science Press, Beijing, China, 2002.

[17] Q. Cheng, F. P. Agterberg, and G. F. Bonham-Carter, "A spatial analysis method for geochemical anomaly separation," Journal of Geochemical Exploration, vol. 56, no. 3, pp. 183-195, 1996.

[18] Q. Cheng, "Spatial and scaling modelling for geochemical anomaly separation," Journal of Geochemical Exploration, vol. 65, no. 3, pp. 175-194, 1999.

[19] Q. Cheng, Y. Xu, and E. Grunsky, "Integrated spatial and spectrum method for geochemical anomaly separation," Natural Resources Research, vol. 9, no. 1, pp. 43-52, 2000.

[20] Q. Cheng, "Mapping singularities with stream sediment geochemical data for prediction of undiscovered mineral deposits in Gejiu, Yunnan Province, China," Ore Geology Reviews, vol. 32, no. 1-2, pp. 314-324, 2007.

[21] Q. M. Cheng, C. Lu, and C. Ko, "GIS spatial: temporal modeling of water systems in greater," Earth Science: Journal of China University of Geosciences, vol. 15, no. 13, pp. 1-8, 2004.

[22] P. Filzmoser, K. Hron, and C. Reimann, "Interpretation of multivariate outliers for compositional data," Computers and Geosciences, vol. 39, pp. 77-85, 2012.

[23] W. Wang, J. Zhao, and Q. Cheng, "Analysis and integration of geo-information to identify granitic intrusions as exploration targets in southeastern Yunnan District, China," Computers \& Geosciences, vol. 37, no. 12, pp. 1946-1957, 2011.

[24] Q. Cheng, F. P. Agterberg, and S. B. Ballantyne, “The separation of geochemical anomalies from background by fractal methods," Journal of Geochemical Exploration, vol. 51, no. 2, pp. 109130, 1994.

[25] R. Ghavami-Riabi, M. M. Seyedrahimi-Niaraq, R. Khalokakaie, and M. R. Hazareh, "U-spatial statistic data modeled on a probability diagram for investigation of mineralization phases and exploration of shear zone gold deposits," Journal of Geochemical Exploration, vol. 104, no. 1-2, pp. 27-33, 2010.

[26] M. A. Gonçalves, A. Mateus, and V. Oliveira, "Geochemical anomaly separation by multifractal modelling," Journal of Geochemical Exploration, vol. 72, no. 2, pp. 91-114, 2001.

[27] U. Kramar, "Application of limited fuzzy clusters to anomaly recognition in complex geological environments," Journal of Geochemical Exploration, vol. 55, no. 1-3, pp. 81-92, 1995.

[28] C. Li, T. Ma, and J. Shi, "Application of a fractal method relating concentrations and distances for separation of geochemical anomalies from background," Journal of Geochemical Exploration, vol. 77, no. 2-3, pp. 167-175, 2003.

[29] P. Roshani, A. R. Mokhtari, and S. H. Tabatabaei, "Objective based geochemical anomaly detection-application of discriminant function analysis in anomaly delineation in the Kuh Panj porphyry $\mathrm{Cu}$ mineralization (Iran)," Journal of Geochemical Exploration, vol. 130, pp. 65-73, 2013.

[30] P. Lenca, P. Meyer, B. Vaillant, and S. Lallich, "On selecting interestingness measures for association rules: user oriented description and multiple criteria decision aid," European Journal of Operational Research, vol. 184, no. 2, pp. 610-626, 2008.
[31] T. Lee, M. Girolami, A. J. Bell, and T. Sejnowski, "A unifying information-theoretic framework for independent component analysis," Computers \& Mathematics with Applications, vol. 39, no. 11, pp. 1-21, 2000.

[32] X. C. Yu, L. W. Liu, D. Hu, and Z. N. Wang, "Robust ordinal independent component analysis (ROICA) applied to mineral resources prediction," Journal of Jilin University (Earth Science Edition), vol. 42, no. 3, pp. 872-880, 2012.

[33] C. Zhao, B. E. Hobbs, H. B. Mühlhaus, A. Ord, and G. Lin, "Convective instability of 3-D fluid-saturated geological fault zones heated from below," Geophysical Journal International, vol. 155, no. 1, pp. 213-220, 2003.

[34] C. Zhao, B. E. Hobbs, A. Ord, S. Peng, H. B. Mühlhaus, and L. Liu, "Double diffusion-driven convective instability of threedimensional fluid-saturated geological fault zones heated from below," Mathematical Geology, vol. 37, no. 4, pp. 373-391, 2005.

[35] C. Zhao, B. E. Hobbs, and A. Ord, "Theoretical analyses of nonaqueous phase liquid dissolution-induced instability in two-dimensional fluid-saturated porous media," International Journal for Numerical and Analytical Methods in Geomechanics, vol. 34, no. 17, pp. 1767-1796, 2010.

[36] C. Zhao, B. E. Hobbs, A. Ord, P. Hornby, and S. Peng, "Morphological evolution of three-dimensional chemical dissolution front in fluid-saturated porous media: a numerical simulation approach," Geofluids, vol. 8, no. 2, pp. 113-127, 2008.

[37] C. Zhao, B. E. Hobbs, P. Hornby, A. Ord, S. Peng, and L. Liu, "Theoretical and numerical analyses of chemical-dissolution front instability in fluid-saturated porous rocks," International Journal for Numerical and Analytical Methods in Geomechanics, vol. 32, no. 9, pp. 1107-1130, 2008.

[38] C. Zhao, B. E. Hobbs, A. Ord, P. Hornby, and S. Peng, "Effect of reactive surface areas associated with different particle shapes on chemical-dissolution front instability in fluid-saturated porous rocks," Transport in Porous Media, vol. 73, no. 1, pp. 7594, 2008.

[39] C. Zhao, B. E. Hobbs, A. Ord, and S. Peng, "Effects of mineral dissolution ratios on chemical-dissolution front instability in fluid-saturated porous media," Transport in Porous Media, vol. 82 , no. 2, pp. 317-335, 2010.

[40] C. Zhao, B. E. Hobbs, and A. Ord, "Theoretical analyses of the effects of solute dispersion on chemical-dissolution front instability in fluid-saturated porous media," Transport in Porous Media, vol. 84, no. 3, pp. 629-653, 2010.

[41] C. Zhao, B. E. Hobbs, and A. Ord, "Effects of medium and porefluid compressibility on chemical-dissolution front instability in fluid-saturated porous media," International Journal for Numerical and Analytical Methods in Geomechanics, vol. 36, no. 8, pp. 1077-1100, 2012.

[42] C. Zhao, Physical and Chemical Dissolution Front Instability in Porous Media: Theoretical Analyses and Computational Simulations, Springer, Berlin, Germany, 2014.

[43] C. Zhao, L. B. Reid, K. Regenauer-Lieb, and T. Poulet, "A porosity-gradient replacement approach for computational simulation of chemical-dissolution front propagation in fluid-saturated porous media including pore-fluid compressibility," Computational Geosciences, vol. 16, no. 3, pp. 735-755, 2012.

[44] C. Zhao, B. E. Hobbs, and A. Ord, "Theoretical analyses of acidization dissolution front instability in fluid-saturated carbonate rocks," International Journal for Numerical and Analytical Methods in Geomechanics, vol. 37, no. 13, pp. 2084-2105, 2013.

[45] C. Zhao, B. E. Hobbs, and A. Ord, "Effects of medium permeability anisotropy on chemical-dissolution front instability in 
fluid-saturated porous media," Transport in Porous Media, vol. 99, no. 1, pp. 119-143, 2013.

[46] A. Hyvärinen, P. O. Hoyer, and M. Inki, "Topographic independent component analysis," Neural Computation, vol. 13, no. 7, pp. 1527-1558, 2001.

[47] C. Jutten and J. Herault, "Blind separation of sources, part I: an adaptive algorithm based on neuromimetic architecture," Signal Processing, vol. 24, no. 1, pp. 1-10, 1991.

[48] P. Comon, "Independent component analysis, A new concept?" Signal Processing, vol. 36, no. 3, pp. 287-314, 1994.

[49] C. Zhao, L. B. Reid, and K. Regenauer-Lieb, "Some fundamental issues in computational hydrodynamics of mineralization: a review," Journal of Geochemical Exploration, vol. 112, pp. 21-34, 2012.

[50] C. Zhao, B. E. Hobbs, and A. Ord, "Theoretical and numerical investigation into roles of geofluid flow in ore forming systems: integrated mass conservation and generic model approach," Journal of Geochemical Exploration, vol. 106, no. 1-3, pp. 251260, 2010.

[51] T. W. Anderson, An Introduction to Multivariate Statistical Analysis, John Wiley \& Sons, New York, NY, USA, 1984.

[52] R. J. Serfling, Approximation Theorems of Mathematical Statistics, John Wiley \& Sons, New York, NY, USA, 1980.

[53] E. Masry, "The estimation of the correlation coefficient of bivariate data under dependence: convergence analysis," Statistics \& Probability Letters, vol. 81, no. 8, pp. 1039-1045, 2011. 


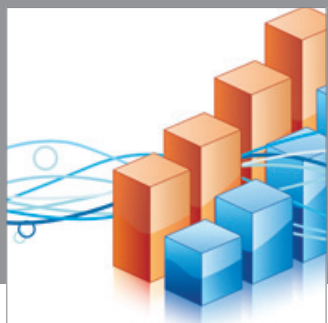

Advances in

Operations Research

mansans

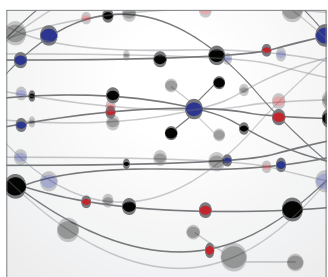

The Scientific World Journal
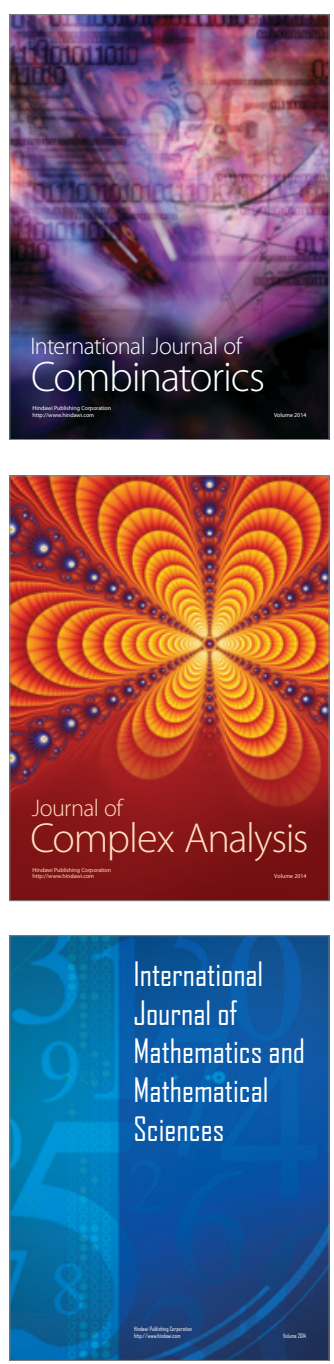
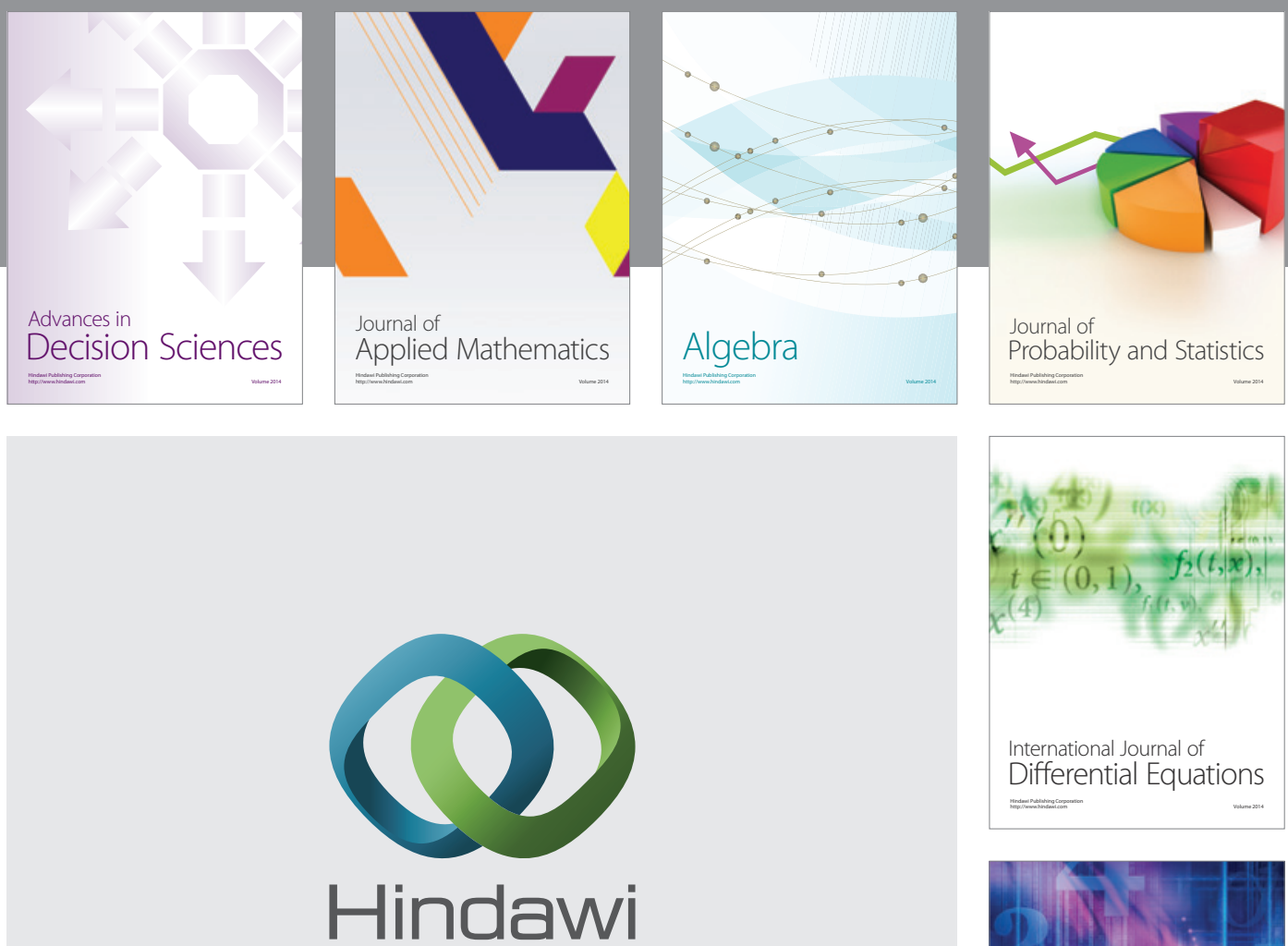

Submit your manuscripts at http://www.hindawi.com
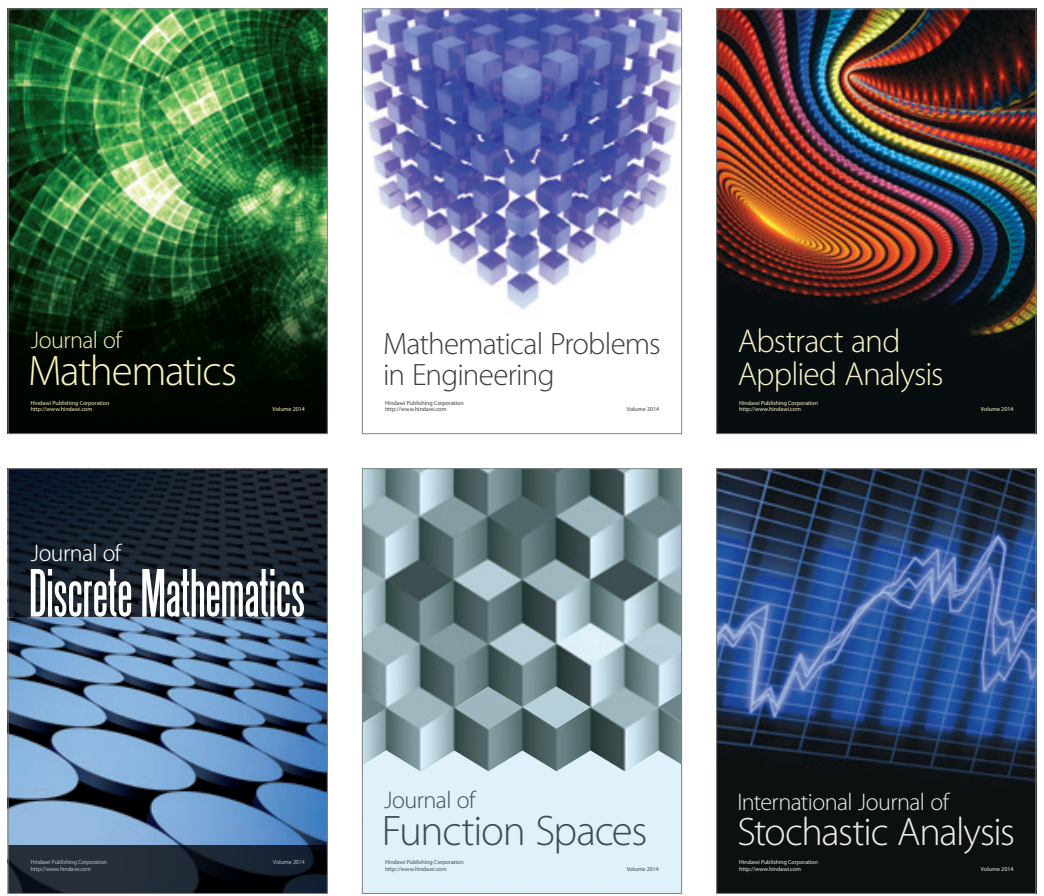

Journal of

Function Spaces

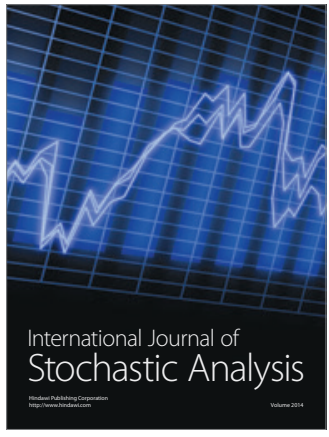

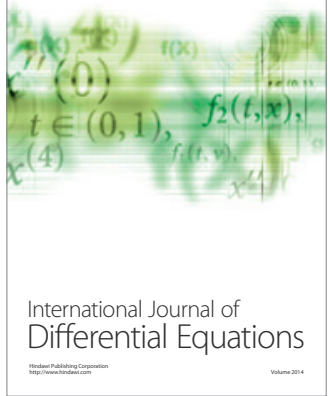
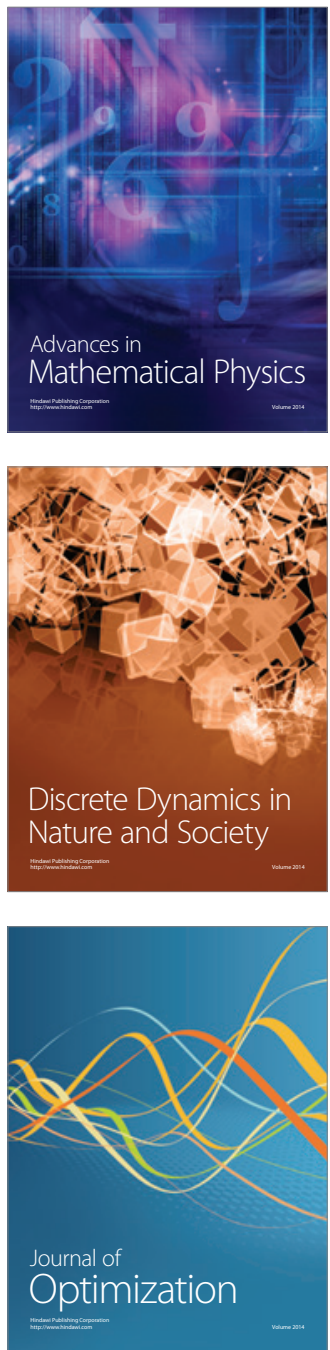